\title{
Dental Suturing Materials and Techniques
}

\author{
Hassan H Koshak* \\ Head of the Dental Department, Ministry of Interior Security Forces Medical Services, Saudi Arabia
}

Submission: November 27, 2017; Published: December 12, 2017

*Corresponding author: Hassan H Koshak, Head of the Dental Department, Ministry of Interior Security Forces Medical Services, Jeddah 21352 , Saudi Arabia, Tel: +966 (0) 555507035; Email: Koshak.hh@gmail.com

\section{Introduction}

Successful dental suturing ororal surgery is dependent on accurate coaptation of the flaps. Various methods and materials have been used (sutures, stents, paste dressings, tissue tacks and adhesives) for precise flap placement. Suturing has remained the most popular method. The term "suture" describes any strand of material utilized to ligate blood vessels or approximate tissues. The primary objective of dental suturing is to position and secure surgical flaps in order to promote optimal healing (first / primary intention) provides support for tissue margin until they heal, without dead space and reduce postoperative pain. Inadequate suturing may result in flap skipping, exposed bone / necrosis, pain and delayed wound healing.

\section{History of the Suture Materials and Classical Literature Review}

The technique of closing wounds by means of needle and thread is several thousand years old. The history of surgical sutures can be traced back to ancient Egypt, and the literature of the classical period contains a number of descriptions of surgical techniques involving sutures. Before catgut became the standard surgical suture material towards the end of the $19^{\text {th }}$ century, many different paths had been followed to find a suitable material for sutures and ligatures. Materials that had been tried included gold, silver and steel wire, silk, linen, hemp, flax, tree bark, animal and human hair, bow-strings, and gut strings from sheep and goats. At the beginning of the $19^{\text {th }}$ century metal threads were tested as suture material. At that time inertness of a material with respect to body tissues was considered an advantage. Nevertheless, metal threads had major disadvantages: their stiffness rendered knot- tying more difficult and could easily result in knot breakage; in addition, suppuration of the wound edges occurred frequently [1-6].

These negative experiences with metal contributed to the establishment of silk as the number one suture material. Wounds sewn with silk cicatrized within a few days, and the small knot caused no problems. For these reasons most surgeons at that time chose silk for sutures and vessel ligatures. A fundamental change in the assessment of suture materials followed the publication in 1867 of Lister's research on the prevention of wound suppuration.
On the basis of work by Koch and Pasteur, Lister concluded that wound suppuration could be prevented by disinfecting sutures, dressings, and instruments with carbolic acid. Initially Lister used silk as a suture material, on the assumption that it was absorbable and therefore could also be used for ligatures. Later he searched for a more rapidly absorbable material and consequently began to use catgut. Catgut is produced from animal connective tissue, in particular bovine sub serosa. Over the years it gradually emerged that animals born and bred in South America were most suitable because they had the lowest fat content thanks to their natural husbandry conditions. The use of catgut was never called into question until the appearance of BSE at the beginning of the 21st century. Alternative products had already been developed by this time. These are the synthetically manufactured absorbable suture materials, which havelargely superseded catgut in Europe. However, catgut continues to play a major role in wound care worldwide. A wide variety of sterilization methods have been tested at various times. Nowadays sutures are mostly sterilized by ethylene oxide or gamma irradiation. In response to the requirements of modern surgery and thanks to the efforts of users and manufacturers over the last few decades, a wide variety of sutures have now been developed $[7,8]$.

\section{Definitions}

a. Suture material is an artificial fibre used to keep wound together until they hold sufficiently well by themselves by natural fibre (collagen), which is synthesized and woven into a stronger scar.

b. Suture is a stitch/series of Stiches made to secure apposition of the edges of a surgical/traumatic wound (Wilkins).

c. Any strand of material utilized to ligate blood vessels or approximate tissues (Silverstein L.H 1999).

\section{Goals}

a. Provide an adequate tension of wound closure without dead space but loose enough to obviate tissue ischemia and necrosis. 
b. Maintain hemostasis.

c. Permit primary intention healing.

d. Provide support for tissue margins until they have healed and the support is no longer needed.

e. Reduce postoperative pain.

f. Prevent bone exposure resulting in delayed healing and unnecessary resorption.

\section{Requisites for suture materials}

a. High uniform tensile strength, permitting use of finer sizes.

b. High tensile strength retention in vivo, holding the wound securely throughout the critical healing period, followed by rapid absorption.

c. Sterile.

d. Pliable for ease of handling and knot security.

e. Freedom from irritating substances or impurities for optimum tissue acceptance.

f. Predictable performance.

g. Prevent or limit bacterial adhesion and proliferation.

h. Uniform diameter.

i. No carcinogenic.

j. Biologically inactive.

With the possible exception of coated Vicryl, none of the sutures available today meet these criteria.

\section{Principles of Suture Selection}

The selection of a suture material by a surgeon must be based on a sound knowledge of the:

a. Healing characteristics of the tissues, which are to be approximated.

b. The physical and biological properties of the suture materials.

c. The condition of the wound to be closed.

d. Probable post-operative course of the patient $[9,10]$.

When a wound has reached maximal strength, sutures are no longer needed. Multifilament sutures should be avoided in contaminated wounds as bacteria can linger within them and may convert it into an infected one. Where cosmetic results are important, close and prolonged apposition of wounds and avoidance of irritants will produce the best results. The smallest inert monofilament suture materials such as polyamide or prolene should be used.

\section{The Ideal Suture}

a. It can be utilized in any operation.

b. It can be handled easily and comfortably.

c. Minimal tissue reaction.

d. High breaking strength.

e. High knot security.

f. It does not cut, tear or shrink the tissue.

g. It is non-allergenic, non-carcinogenic

h. It is absorbed predictably with no tissue reaction.

i. It is reasonably priced.

\section{Suture's Physical Characteristics}

\section{The Physical Configuration}
a. Monofilamentous or multifilamentous.
b. Twisted or braided.

\section{The Tensile Strength}

a. The weight required to break a suture, divided by its cross sectional area.

b. Identified by a different number of zeros.

\section{The Knot Strength}

a. The amount of force needed to cause a knot to slip.

b. It is proportional to the coefficient of friction of the material.

The Elasticity: The ability of a suture to regain its original form and length after being stretched.

The Plasticity: The ability of a suture to expand when stretched, but not to return to its initial length.

The Memory: The ability of a suture to return to its former shape after being manipulated. It's a reflection of its stiffness.

\section{Classification of Suture Materials}

a. According to fate: Absorbable or Non-absorbable (Figure

1).

b. According to source: Natural or Synthetic.

c. According to structure: Monofilament or Multifilament.

d. According to coating: Coated or Uncoated, Dyed or Undyed.

e. According to tissue reaction: Reactive or Not reactive.

f. According to handling: Easy or Difficult to handle. 

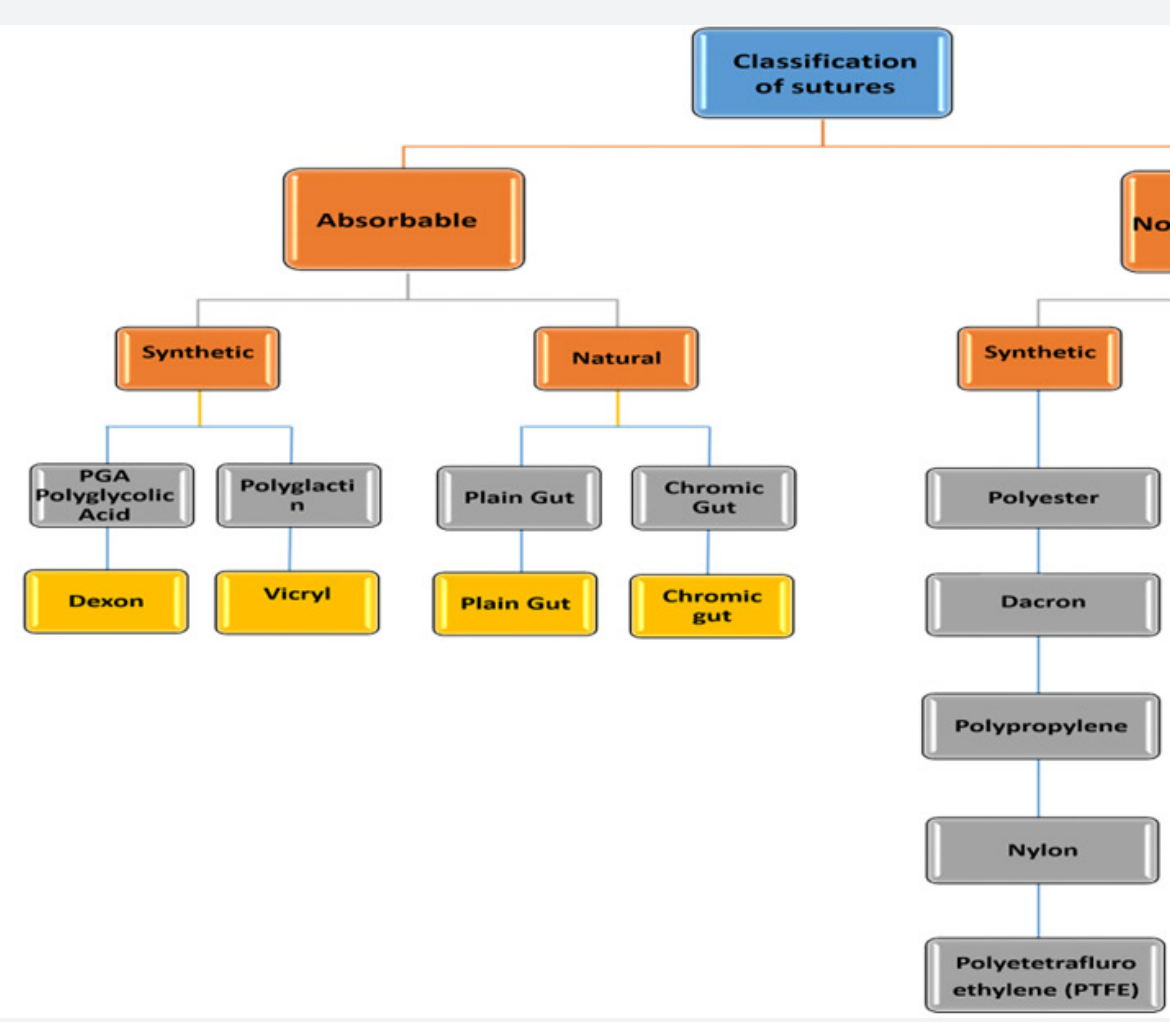

Figure 1: Classification of suture materials.

\section{Absorbable Sutures}

Popular in periodontal and implant surgeries, less postoperative inflammation, more patient's comfort and it is availablein two forms natural or synthetic.

Natural Absorbable Sutures: Monofilaments of highly purified collagen, mild to moderate tensile strength, mild inflammatory reaction, and difficult to handle. Should not be used in high acidic environment (reflux bulimia, esophagitis, Sjogern'ssyndrom, radiation therapy). Available in two types:

a. Plain Gut resorption rate from 3 to 5 days.

b. Chromic Gut: Dyed with chromium salt solution and prolonged resorption rate from 7 to 10 days.

Synthetic Absorbable Sutures: Braided filaments - polyglycolic acid (P.G.A), PGA is absorbed by hydrolysis (hydrophobic), good tensile strength (resist muscle pull), bacterial growth inhibition, mild tissue reaction, and resorption rate from 21 to 28 days. Available in two types:

a. Dexon®: Non-toxic coating or uncoted, violet or undyed.

b. Vicryl: Coated - violet or undyed, stronger than Dexon [11].

How the resorption of sutures occurs? a. Enzymatic degradation for animal protein.

b. Hydrolysis.

c. The speed of absorption is roughly proportional to the vascularity of surrounding tissue.

\section{Non-absorbable Sutures}

Materials suitably resistant to the action of living mammalian tissue. Treated for capillarity (the passage of tissue fluid along the strand permitting infection). Patient's discomfort and it is available in two forms natural and synthetic.

\section{Natural Non-absorbable Sutures}

a. Silk: Braided siliconized proteinogenous suture derived from silk worms, superior handling quality, high elasticity, good knot security, black dyed for easy visibility, bacteria and fluid collection (Wick effect), high potential for infection, and severe inflammatory reaction.

b. Cotton/Linen: Braided / twisted filaments, easy to handle, poor strength, and severe inflammatory reaction.

\section{Synthetic Non-absorbable Sutures:}

a. Nylon: Braided (coated) or nonbraided, mono / multifilament's, Excellent handling quality, excellent knot security, greater tensile strength than silk, no inflammatory reaction, monofilaments have a tendency to return to their original state memory. 
b. Polypropylene: Monofilament, excellent tensile strength, no inflammatory reaction, and difficult to handle.

c. Polyester: Braided coated or uncoated and not tissue reaction. Dacron, uncoated excellent knot security.

d. Ethibond: Coated, more gentle with tissue and less knot security.

e. Polytetrafluroethylene (PTFE)/Gore-Tex: Monofilament, high tensile strength, excellent handling properties, low tissue reaction but it is very expensive (Figure 2).

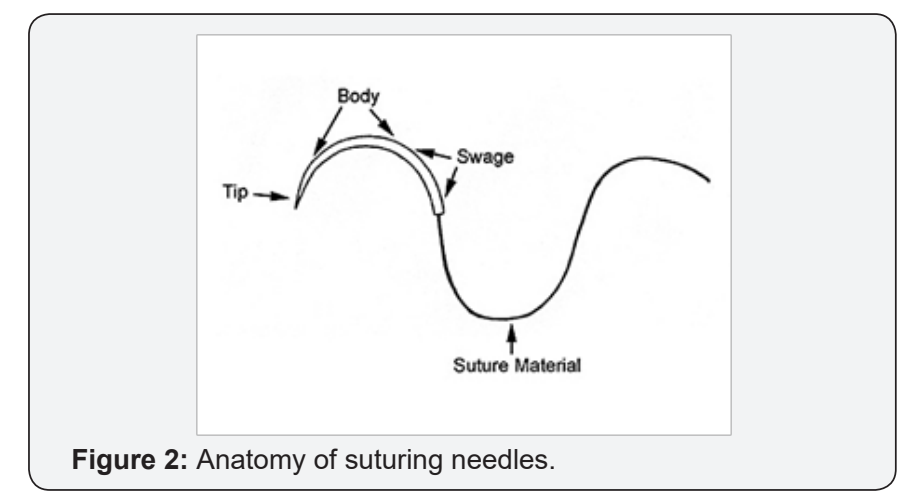

\section{Selection of suture material}

A variety of suture materials and suture/needle combinations are available. The choice of suture for a particular procedure is based on the known physical and biologic characteristics of the suture material and the healing properties of the sutured tissues. The selection of suture material is based on: The condition of the wound, the tissues to be repaired, the tensile strength of the suture material, knot-holding characteristics of the suture material, and the reaction of surrounding tissues to the suture materials [12].

\section{Suture Needles}

Surgical needles are designed to lead suture material through tissue with minimal injury. Needles can be:

a. Straight (limited use in oral surgery) or curved (Figure 3).

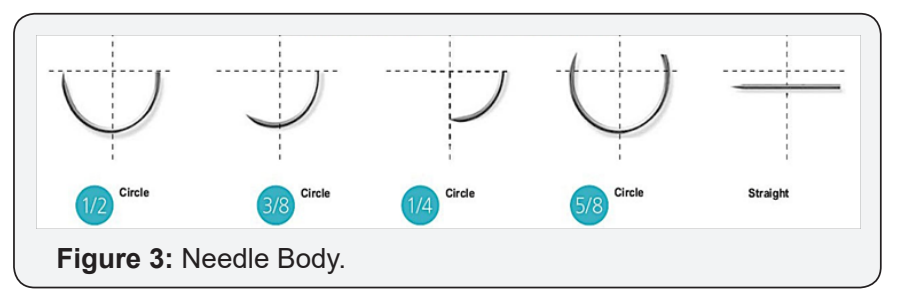

b. Swaged or eyed. Made up of either SS or carbon steel.

\section{Classification of surgical needles}

According to eye: Eye less needles. -Needles with eye.

According to shape: Straight needles. -Curved needles.

According to cutting edge: Round body. Cutting: a-conventional. b-reverse cutting.
According to its tip: Triangular tip. -Round tip -Blunt tip.

Others: Spatula needles. Micro point needles. Cuticular needles. -Plastic needles.

\section{Ideal properties of needles}

a. High quality stainless steel.

b. Smallest diameter possible.

c. Capable of implanting sutures with minimal trauma to tissues.
d. Stable in the needle holder.
e. Should be sharp.
f. Sterile and corrosion resistant.

\section{Anatomy of suturing needles}

Three basic components (Figure 2):
i. $\quad$ Press - fitted end (swage)
ii. Needle body
iii. Needle point

\section{Swaged needle}

a. Swaged needles do not require threading and permit a single strand of suture material to be drawn.

b. Suture attached to needle via a hole drilled through the end of the needle, and the end is swaged during manufacturing.

c. Atraumatic and act as a single unit.

d. Prepacked and presterilized by gamma radiation [13-16].

\section{Needle body}

Body is the widest portion of the needle, it is known as grasping area. Most commonly used are 3/8 circlesin oral cavity (Figure 3). They can be easily manipulated in large and superficial wounds and require only less wrist movement. $1 / 2$ circle used for suturing tissues in small wounds, and body cavities and orifices. Require less space, but more supination and pronation of wrist required.

\section{Needle point}

Point runs from tip to the max, cross sectional area of the body. Can be:-Triangular tip/cutting. -Round tip. -Blunt tip (Figure 4). Cutting needles are Ideal for suturing keratinized tissues like palatal mucosa and for securing drains. Round/tapered needles used for closing mesenchymal layers such as muscle or fascia that are soft and easily penetrable. The conventional cutting point has two opposing cutting edges and third edge on the inside curvature of the needle. The reverse cutting point has two opposing cutting edges and third cutting edge on the outer curvature of the needle. The tapered point is used primarily on soft, easily penetrated tissues. It leaves small hole and can be used in vascular surgery as well as facial soft tissue surgery. The blunt point has a rounded end, which does not cut through the tissue [17]. 


\section{Global Journal of Otolaryngology}

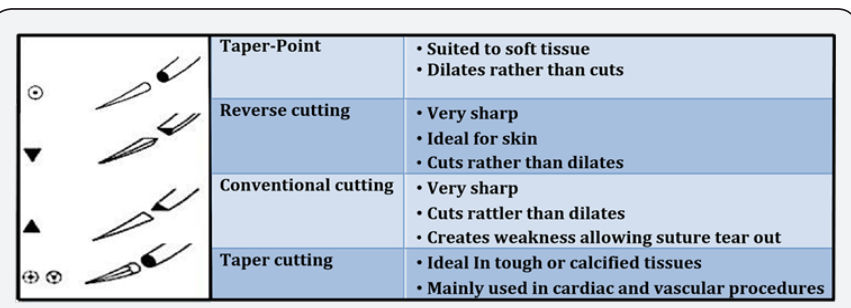

Figure 4: Needle point geometry.

\section{Suture size}

Diameter of surface material it is measured in sizes from 1-0 to $10-0.10-0$ is the smallest diameter and least amount of tensile strength. Tensile strength of the suture should never exceed the tensile strength of the tissue, it holds4-0 is most commonly used in periodontal flap surgeries, 5-0 is mostly used for delicate tissues and for soft tissue graft surgery.

\section{Needle is selected according to:}

a. Type of tissue to be sutured,

b. Tissue's accessibility,

c. Diameter of suture material.

\section{Suturing Instruments}

It is important to have good quality instruments that are the correct size for the location and nature of the wounds being closed. The instruments also need to be correctly sterilized and handled carefully. Some of the suturing instruments like scissors, tissue forceps, and needle holder (Figure 5).

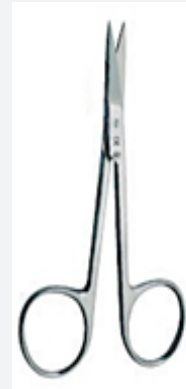

Scissors
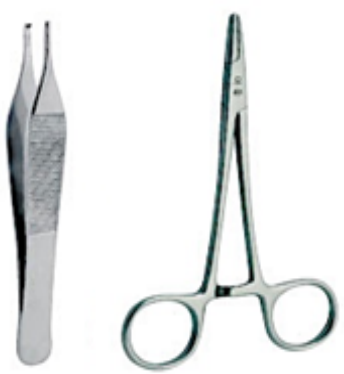

Tissue forceps Needle holder
Figure 5: Suturing Instruments.

\section{Suture size}

Diameter of surface material it is measured in sizes from 1-0 to $10-0.10-0$ is the smallest diameter and least amount of tensile strength. Tensile strength of the suture should never exceed the tensile strength of the tissue, it holds4-0 is most commonly used in periodontal flap surgeries, 5-0 is mostly used for delicate tissues and for soft tissue graft surgery.

\section{Needle is selected according to}

a. Type of tissue to be sutured,

b. Tissue's accessibility, c. Diameter of suture material.

\section{Suturing Instruments}

It is important to have good quality instruments that are the correct size for the location and nature of the wounds being closed. The instruments also need to be correctly sterilized and handled carefully. Some of the suturing instruments like scissors, tissue forceps, and needle holder (Figure 4) [18-21].

\section{General clinical principles}

a. Do not take too-small bites of tissues so that the suture tears through the wound edges. The needle should enter the tissue approximately 2-3 $\mathrm{mm}$ front the wound edge or papillae tip.

b. Do not attempt to bridge the tissues with the needle. It is not advisable to pass the suture through the facial and lingual papillae in one pass.

c. If the needlepoint is dull, do not try to force it through the tissues - stop, get a new sharp needle and then suture.

d. Sutures should always be inserted through the more mobile tissue flap first.

e. When penetrating through tissues, the needle should enter at right angles to the tissue.

f. Suture needles are grasped in the center (or about $1 / 3$ the distance from the swaged area to the tapered point of the needle) and only by needle holder, and are inserted and pulled through the tissue in line with the circle. The suture is pulled just tightly enough to secure the flap in place without restricting the blood supply.

g. The flaps should not be blanched when tying a suture.

h. Sutures should be placed no closer than 2-3 $\mathrm{mm}$ from the edge of the flap to prevent tearing through the flap during the swelling that occurs 24-48 Hours post-operative [22-25].

\section{Principles of suturing techniques}

a. The needle holder should grasp the needle at approximately $1 / 3$ of the distance from the end. (Figure 6).

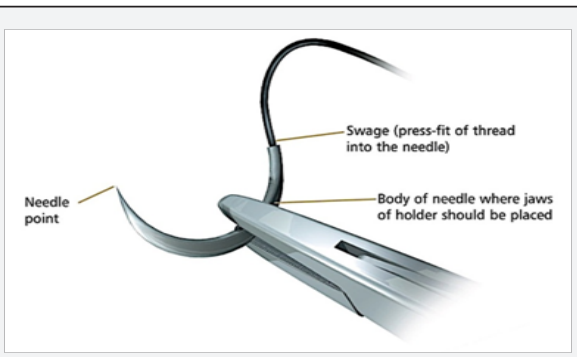

Figure 6: Proper location on the needle body for grasping by the needle holder.

b. The needle should enter the tissue perpendicular to the surface. If the needle pierces the tissue obliquely, a tear may develop. 
c. The needle should be passed through the tissue following the curve of the needle.

d. The suture should be placed at an equal distance from the incision on both the sides and at an equal depth.

e. The needle should pass from the free tissue to the fixed side.

f. If one tissue side is thinner than the other the needle should pass from the thinner tissue to the thicker one.

g. If one tissue plane is deeper than the other, then the needle should pass from the deeper to the superficial side.

h. The distance that the needle is passed into the tissue should be greater than the distance from the tissue edge.

i. $\quad$ Avoid excessive tissue bites with small needles, as it will be difficult to retrieve them.

j. The tissues should not be closed under tension, since they will tear or necrosis around the suture. If tension is present the tissues should be undermined to relieve it.

k. The suture should be tied so that the tissue is merely approximated and the edges are everted.

l. The knot should not be placed over the incision line [26].

m. Sutures should be placed approximately $3-4 \mathrm{~mm}$ apart.

n. Closer spaced sutures are indicated in areas of tension.

\section{Suturing techniques}

a. Simple loop modification of interrupted suture technique.

b. Continuous non-interlocking suture technique.

c. Continuous locking suture technique.

d. Vertical mattress suture technique.

e. Horizontal mattress suture technique.

f. Continuous horizontal mattress suture technique.

g. Modification of interrupted suture technique.

h. Cross (Crisscross) suture technique.

i. Periosteal Suturing Technique.

j. Coronally repositioned mattress suture technique.

k. Vertical sling mattress suture technique.

l. Single interrupted sling suture technique.

m. Sling suture about single tooth.

n. Independent sling suture technique. o. Continuous independent sling suture technique.

The Most Used Suturing Techniques in Oral Cavity

\section{Interrupted simple suture}

Most commonly used. Inserted singly through side of the wound and tied with a surgeon's knot (Figure 7).

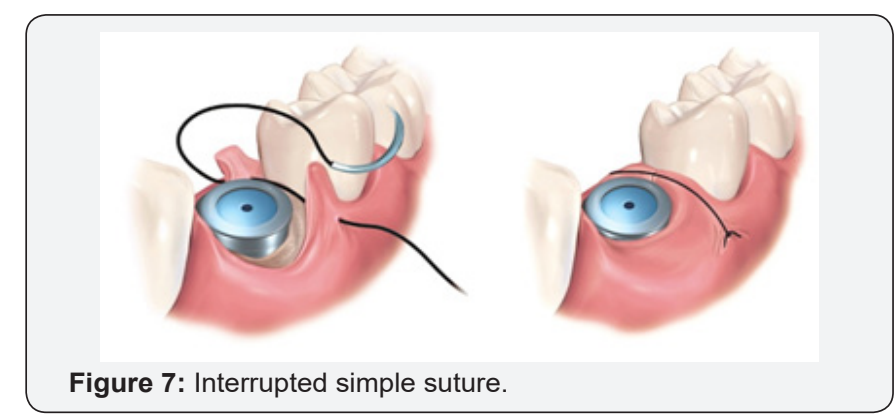

\section{Advantages}

a. Strong and can be used in areas of stress.

b. Placed 4-8 $\mathrm{mm}$ apart to close large wounds, so that tension is shared.

c. Each is independent and loosening one will not produce loosening of the other.

d. Degree of eversion produced.

e. In infection or hematoma, removal of few sutures.

f. Free of interferences between each stitch and easy to clean.

\section{Simple continuous/running}

A simple interrupted suture placed and needle reinserted in a continuous fashion such that the suture passes perpendicular to the incision line below and obliquely above. Ended by passing a knot over the untightened end of the suture.

\section{Advantages}

a. Rapid technique and distributes tension uniformly.

b. More water tight closure.

c. Only 2 knots with associated tags.

\section{Disadvantages}

If cut at one point, suture slackens along the whole length of the wound, which will then gape open.

\section{Continuous locking/blanket}

Similar to continuous but locking provided by withdrawing the suture through its own loop (Figure 8). Indicated in long edentulous areas, tuberosity or retromolar area. 


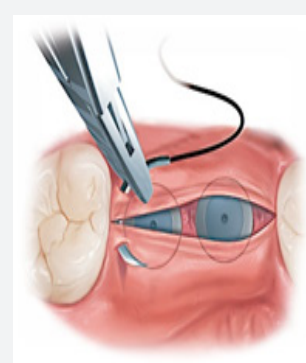

Figure 8: Continuous locking suture.

\section{Advantages}

a. Will avoid multiple knots

b. Distributes tension uniformly

c. Watertight closure

d. Prevents excessive tightening.

\section{Disadvantage}

Prevents adjustment of tension over suture line as tissue
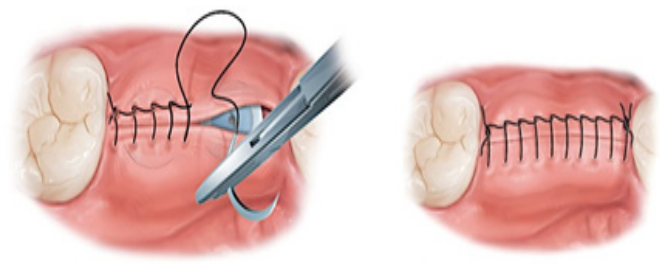

swelling occurs.

\section{Vertical Mattress}

Internal vertical mattress (Figure 9): It passes at 2 levels, one deep to provide support and adduction of wound surfaces at a depth and one superficial to draw the edges together and Evert them. Used for closing deep wounds. Needle passed from one edge to the other and again from latter edge to the fist and knot tied. When needle is brought back from second flap to the first, depth of penetration is more superficial.
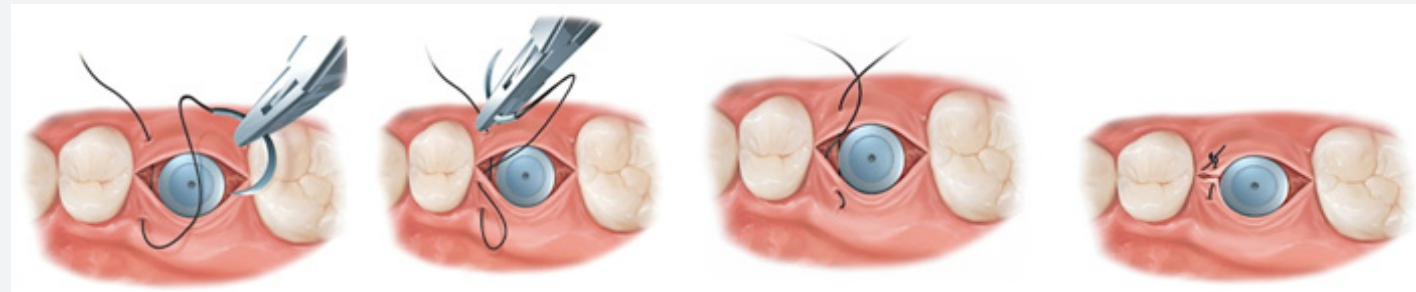

Figure 9: Internal vertical mattress suture.

\section{Advantages}

i. For better adaptation and maximum tissue approximation.

ii. To get eversion of wound margins slightly.

iii. Where healing is expected to be delayed for any reason, it is better to give wound added support by vertical mattress. Used to control soft tissue hemorrhage.

iv. Runs parallel to the blood supply of the edge of the flap and therefore not interfering with healing.

\section{Horizontal Mattress}

It everts mucosal margins, bringing greater areas of raw tissue into contact. So used for closing bony deficiencies such as oro-antral fistula or cystic cavities (Figure 10).
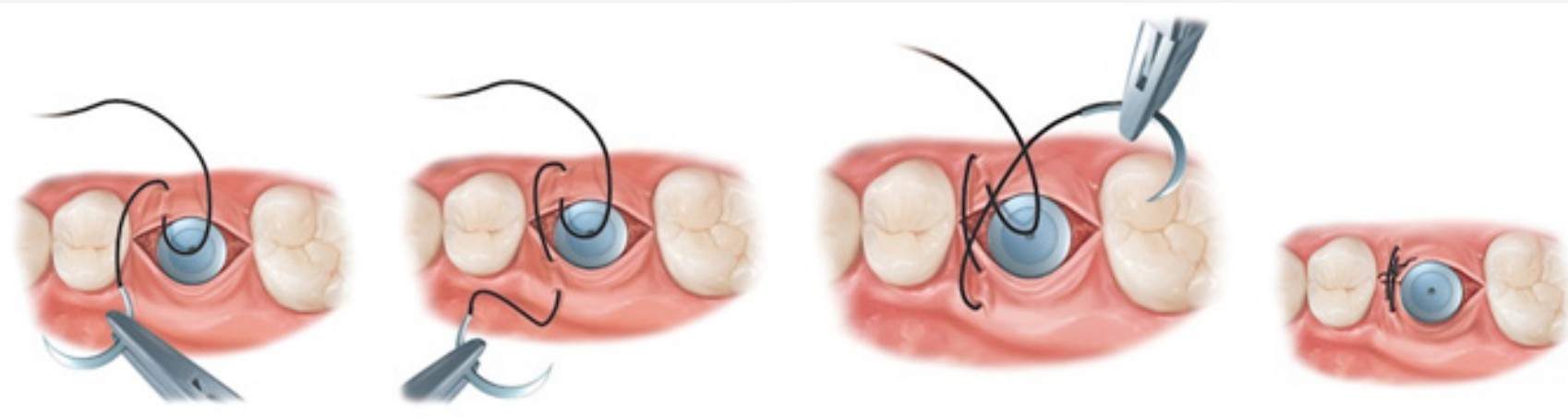

Figure 10: External vertical mattress suture. 


\section{Disadvantage}

a. Constricts the blood supply to edges of incision.

b. Needle passed from one edge to the other and again from the latter to the first and a knot is tied.

c. Distance of needle penetration and depth of penetration is same for each entry point, but horizontal distance of the points of penetration on the same side of the flap differs.

\section{Advantages}

a. Will evert mucosal margins, bringing greater areas of raw tissue into contact. -So used for closing bony deficiencies such as oro-antral fistula or cystic cavities, extraction socket wounds.

b. Prevents the flap from being inverted into the cavity.

c. To control post-operative hemorrhage from gingiva around the tooth socket to tense the mucoperiosteum over the underlying bone.

d. It does not cut through the tissue, so used in case of tissue under tension (inadequate tissue) Disadvantages: e. More trouble to insert.

f. Constricts the blood supply to the incision if improperly used, cause wound necrosis and dehiscence.

\section{Figure 8 modification of interrupted suture technique}

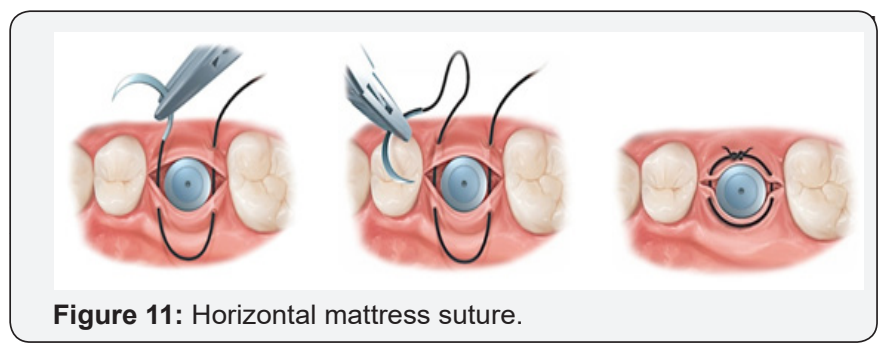

\section{Cross (Crisscross) suture}

This suture is used over edentulous spaces (Figure 12). When beginning this technique, a $3 / 8$ circle needle penetrates at the level of the mucogingival junction at the mesiobuccal line, travels horizontally under the flap, and emerges at the distobuccal line angle, the procedure is done on the lingual aspect,the suture material crosses over the surgical field, tying of suture knot on buccal aspect forming a cross on the flap.
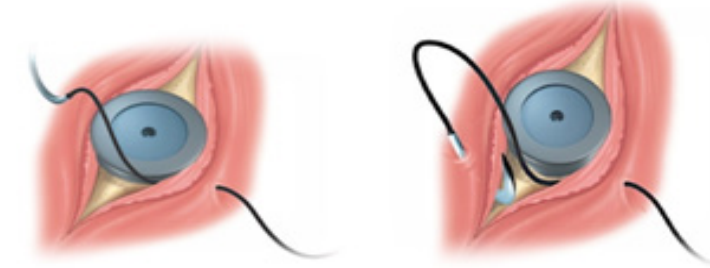
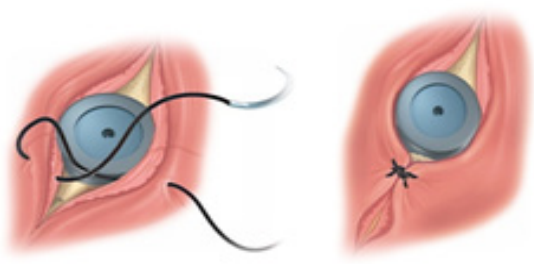

Figure 12: Figure 8 suture.

\section{Sling suture about single tooth}

The $3 / 8$ circle reverse cutting needle is first passed under the distal contact point of the most distal interdental papilla (Figure 13). then the suture needle pierces through the inner side of the elevated surgical flap $3 \mathrm{~mm}$ from the tip of the papilla, passage of the suture needle back under the contact point, then passed under the next contact point in a mesial direction and then the needle pierces through the inner surface of the elevated surgical flap $3 \mathrm{~mm}$ from the tip of the interdental papilla, then passage of the needle back under the contact point, tying of the suture knot on the non elevated tissues.
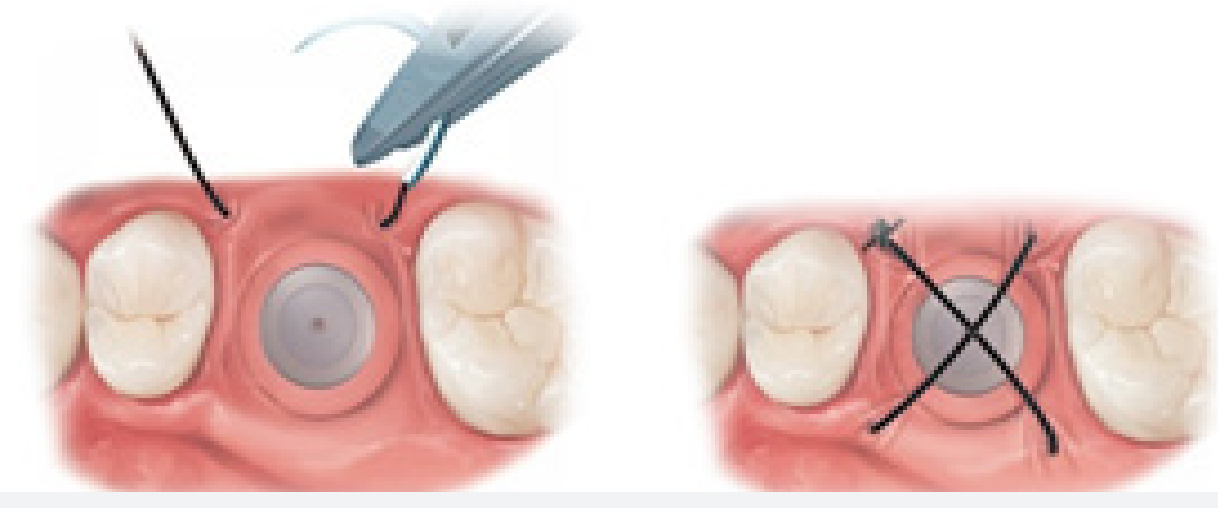

Figure 13: Cross suture. 


\section{Periosteal Suturing Technique}

The periosteal suture technique involves penetrating the periodontal/peri implant tissues and periosteum all the way to the bone (Figure 14), followed by rotation of the needle back toward the direction it started, while penetrating through the periosteum again, then back through the keratinized tissue. A $180^{\circ}$ rotation of the needle grabbing the periosteum, the needle is moved along the bone below the periosteum, rotation about the needle body, permitting the point to exit the periosteum and tissue.

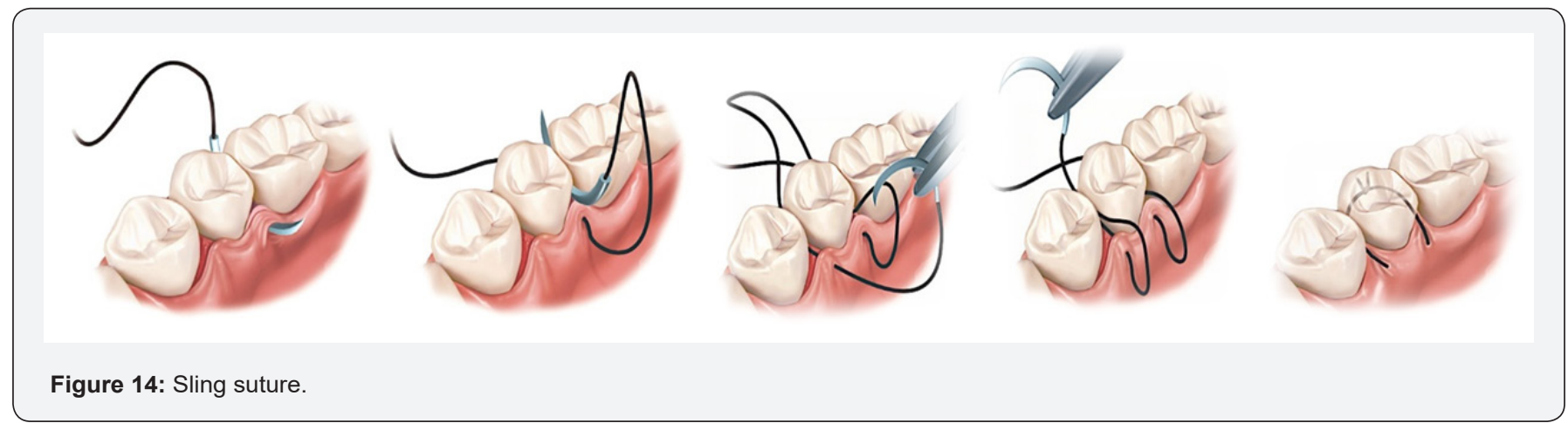

Figure 14: Sling suture

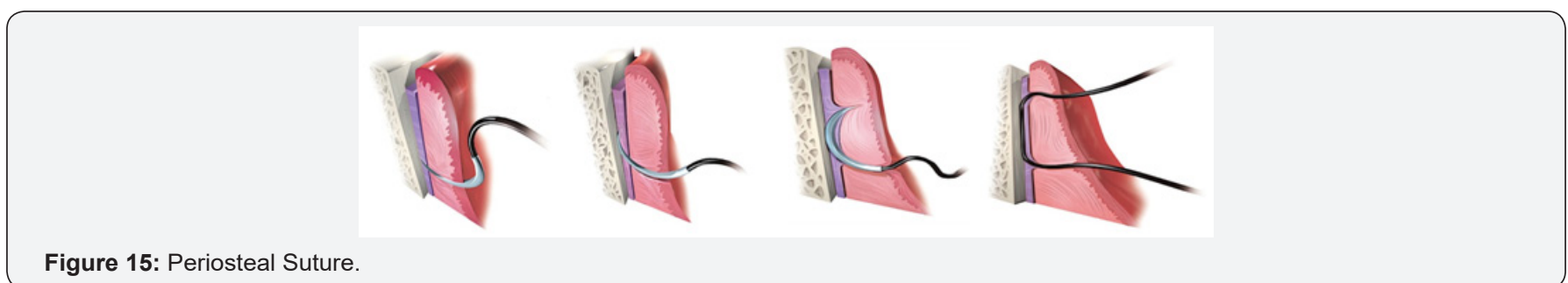

\section{Knotes and Knotes Tying}

"Suture security is the ability of the knot and the material to maintain the tissue approximation during healing process."

\section{Components of a knot}

a. The loop created by the knot (Figure 15).

b. The knot itself, which is composed of a number of tight "throws"; each throw represents a weave of the two strands.

c. The ears, which are the cut ends of the suture.

\section{Types of the knot}

Square knot: This suture knot is made by tying two overhand knots, each done in opposite directions (Figure 16). For example, the first loop is made by making a loop over the jaws of the needle holder, and the second knot is subsequently made by forming a loop under the jaws of the needle holder. This knot is easy to tie, but may loosen when a synthetic or monofilament suture material is used.

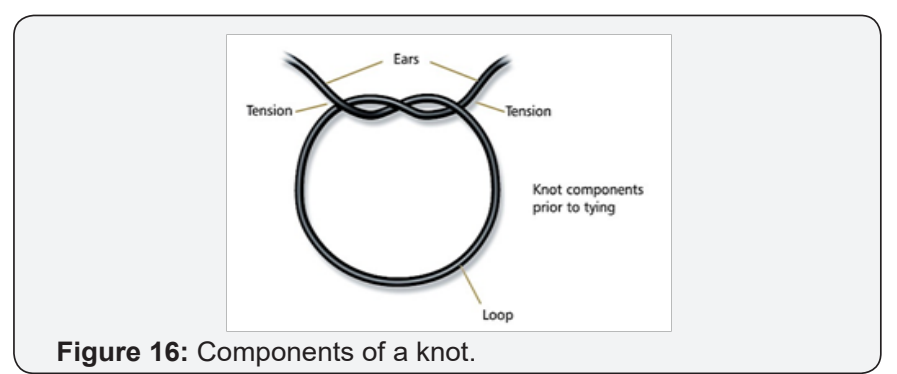

Surgical knot: This knot is used primarily with braided suture material, whether synthetic or natural (Figure 17). The surgeon's knot is a modified square knot in which the first overhand knot is doubled; therefore, two loops of the suture are formed over the jaws of the needle holder and tightened. The last loop is formed under the jaws of the needle holder in a direction opposite from the first loops. This is the standard suture knot used in conjunction with the mattress technique of suturing. Note: When synthetic or natural resorbable sutures are used, one additional overhand knot may be added to the surgeon's knot to prevent unraveling.

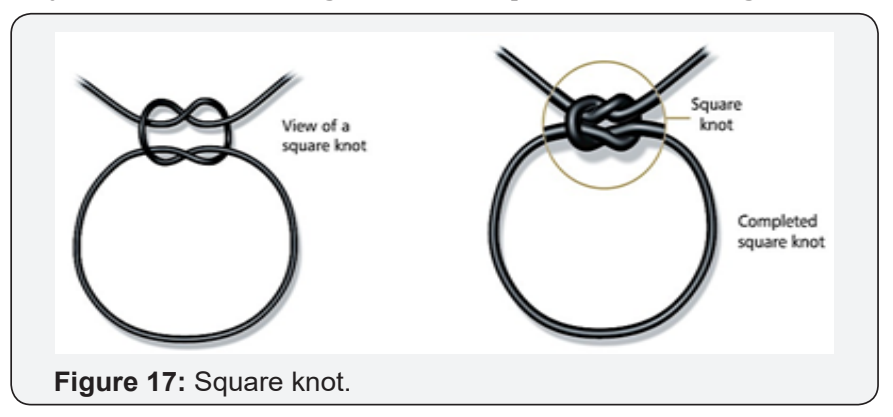

Granny knot: The slipknot is similar to a square knot in that it is made with two overhand knots, but both knots are made in the same direction (Figure 18). With a needle holder, one overhand knot is made so that the loop forms over the jaws of the needle holder and is then tightened. A second overhand knot is then made so that the loop goes in the same direction over the needle holder and is tightened. 


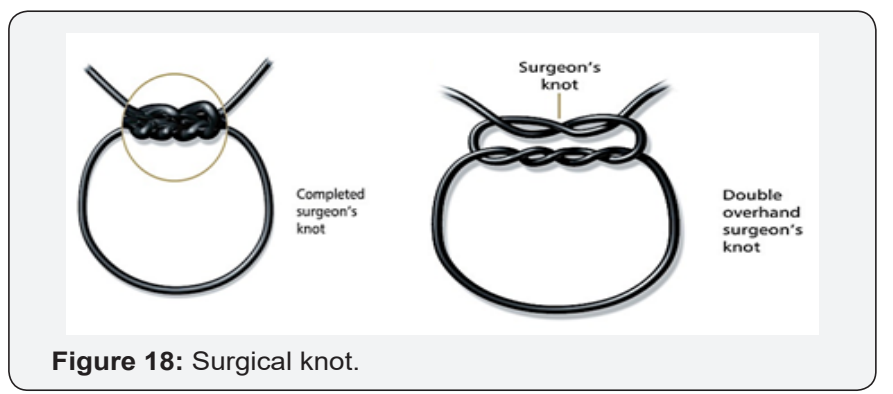

\section{Suture Removal}

The time to suture removal depends on the location and the degree of tension the wound was closed under. This varies between surgeon and situation, but as a general rule sutures on the gums and oral cavity are usually removed between ten and fourteen days post-operatively. To remove sutures, one tail of the suture should be grasp with forceps and pulled gently towards one side to the wound, elevating the knot. The opposite side of the suture should then be cut with stitch-cutters or fine suture scissors immediately under the knot. The suture can then be pulled out of the tissue by pulling towards the opposite side of the wound (Figure 19).

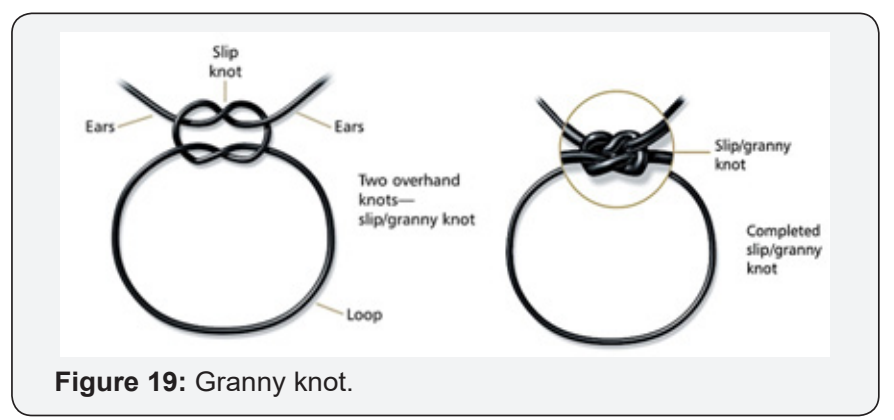

Conclusion

Knowledge of the suture, needles (type, size, shape), instruments, and techniques are absolutely necessary in order to be a competent surgeon. There is no suture superior to the others in each aspect. The differences in terms of tissue reaction and bacterial adhesion between sutures should be always considered in the selection of the appropriate suturing material. Delicate and proper soft tissue handling during various suturing techniques can insure optimal tissue healing and high esthetic result.

\section{References}

1. Miguel GS Andrade, Ruben Weissman, Sílvia RA Reis (2005) Tissue Reaction and Surface Morphology of Absorbable Sutures after In Vivo Exposure. Journal of Material Science: Material Medicine 17(10): 949961.
2. Edward S Cohen Atlas of cosmetic and reconstructive periodontal surgery $2^{\text {nd }}$ Edn. Harry Dym Atlas of Minor Oral Surgery.

3. Baldi C, Pini Prato G, Pagliaro U, Nieri M, Saletta D, et al (1999) Coronally advanced flap procedure for root coverage. Is flap thickness a relevant predictor to achieve root coverage? A 19-case series. J Periodontol 70(9): 1077-1084.

4. Braun, Aesculap (2006) Suture Glossary.

5. Chrimax (2001) Non-absrobable Materials: Reactionin Tissue.

6. Dunn DL (2007) Wound Closure Manual. Johnson and Johnson Engineering. Toolbox (2012) Stiffness. (2012) Engineering Toolbox, Stiffness.

7. (1985) Wound closure manual, Ethicon, Somerville, New Jersey, USA.

8. Helmenstine AM (2012) Strain About.com Chemistry.

9. Goeffrey L.Howe, Minor Oral Surgery.

10. Najibi S, Banglmeier R, Matta JM, Tannast M (2010) Material Properties of Common Suture Materials in Orthopaedic Surgery. Iowa Orthopaedic Journal 30: 84-88.

11.W Harry Archer, Oral and Maxillofacial Surgery.

12. (2004) Oral tissue reaction to suture materials: A review Periodontal Abstracts: 52: 237-244.

13. Postlethwait RW, Willigan D A, Ulin AW (1975) Human Tissue Reaction to Sutures. Annals of Surgery 181(2): 144-150.

14. Ratner BD, Hoffman A, Schoen F, J Lemons (2004) Surface Properties and Surface Characterization of Materials. Biomaterial Science: An Introduction to Material in Medicine. ( $2^{\text {nd }}$ edn). San Diego, US.

15. Salhan S, Dass A (2012) Textbook of Gynecology. Jaypee Brothers Medical, New Delhi,India.

16. Surgical Knot tying Ethicon manual, Somerville, New Jersey, USA.

17. Suture material techniques and knots. Serag wieesner, Naila, Germany.

18. Sandro Siervo, Suturing techniques in oral surgery.

19. Carranza , Textbook of clinical periodontology, $10^{\text {th }}$ edn.

20. Daniel MLaskin, Text book of oral and maxillofacial surgery.

21. Neelima Anil Malik, Textbook of oral and maxillofacial surgery.

22. S.M.Balaji, Text book of oral and maxillofacial surgery.

23. Louis F Rose, Brian L Mealey, Textbook of Periodontics.

\section{US Pharmacopeia.}

25. Postlethwait RW (1971) Wound healing and surgery, Ethicon, Somerville, New Jersey, USA.

26.Zucchelli G, De Sanctis M (2007) The coronally advanced flap for the treatment of multiple recession defects: a modified surgical approach for the upper anterior teeth. J Int Acad Periodontol 9(3): 96-103. 
This work is licensed under Creative Commons Attribution 4.0 License

DOI: $10.19080 /$ GJO.2017.12.555833
Your next submission with Juniper Publishers will reach you the below assets

- Quality Editorial service

- Swift Peer Review

- Reprints availability

- E-prints Service

- Manuscript Podcast for convenient understanding

- Global attainment for your research

- Manuscript accessibility in different formats

( Pdf, E-pub, Full Text, Audio)

- Unceasing customer service

Track the below URL for one-step submission https://juniperpublishers.com/online-submission.php 